\title{
A case of schizophrenia comorbid for tetralogy of Fallot treated with clozapine: further considerations on a role for 22q. 11.2 in the proneness for seizures
}

\author{
This article was published in the following Dove Press journal: \\ Neuropsychiatric Disease and Treatment \\ 29 August 2017 \\ Number of times this article has been viewed
}

\author{
Hiroko Kashiwagi' \\ Satoru Ikezawa ${ }^{2}$ \\ Tomiki Sumiyoshi ${ }^{3}$ \\ Atsuko Kadono ${ }^{4}$ \\ Kazuhiko Segawa ${ }^{5}$ \\ Kazuyoshi Takeda' \\ Mayu Omori' \\ Hisako Taguchi' \\ Naotsugu Hirabayashi' \\ 'Department of Forensic Psychiatry, \\ ${ }^{2}$ Department of Psychiatry, \\ ${ }^{3}$ Department of Clinical Epidemiology, \\ Translational Medical Center, National \\ Center Hospital of Neurology \\ and Psychiatry, Kodaira, Tokyo, \\ ${ }^{4}$ Saitama Psychiatric Medical Center, \\ Kitaadatigun, Saitama, ${ }^{5}$ Department of \\ General Medicine, National Center \\ Hospital of Neurology and Psychiatry, \\ Kodaira, Tokyo, Japan
}

\begin{abstract}
We present a case of schizophrenia comorbid for tetralogy of Fallot, without chromosome 22q.11.2 deletion or duplication, treated successfully with a combination of clozapine and antiepileptic drugs. Although clozapine by itself initially triggered convulsive seizures, we continued it with co-administration of valproate and topiramate. This combined treatment did not affect cardiac function of the patient, who experienced a favorable clinical course in terms of symptomatology and functional outcomes. To our knowledge, we provide the first report on a patient with tetralogy of Fallot, in whom 22q.11.2 was not deleted and clozapine-induced seizures were observed.
\end{abstract}

Keywords: schizophrenia, clozapine, tetralogy of Fallot, seizure, copy number variants

\section{Introduction}

Tetralogy of Fallot is characterized by ventricular septal defects, aortic overriding, right ventricular outflow stenosis, and right ventricular hypertrophy. It accounts for 3\%-5\% of all congenital heart disease cases, with an incidence rate of 0.28 per $1,000 .{ }^{1}$ Chromosome 22 q. 11.2 deletion has been reported in nearly $25 \%$ of patients with tetralogy of Fallot. ${ }^{1}$ Likewise, $\sim 25 \%$ of individuals with 22q. 11.2 deletion have the disease. ${ }^{2}$

Schizophrenia has been reported to occur in $\sim 25 \%$ of individuals with $22 \mathrm{q} .11 .2$ deletion. ${ }^{1}$ Patients with treatment-resistant schizophrenia with 22 q. 11.2 deletion but without a history of epilepsy are prone to convulsive seizures induced by clozapine, even when relatively low doses are administered. ${ }^{3}$

The incidence of clozapine-induced seizure was reported to be $\sim 5 \%$ (for a 1-year period), and $4 \%-6 \%$ to $22 \%$ over different time frames. ${ }^{4}$

Here, we describe a case of treatment-resistant schizophrenia comorbid for tetralogy of Fallot that was successfully treated with clozapine. Although clozapine initially triggered convulsive seizures, its administration was continued in combination with antiepileptic drugs. The treatment did not affect the cardiac function of the patient, who experienced a favorable clinical course. The implications for the role of 22q.11.2 copy number variants (CNVs) in clozapine-induced seizures are re-considered.

Correspondence: Hiroko Kashiwagi Department of Forensic Psychiatry, National Center Hospital of Neurology and Psychiatry, 4-I-I, Ogawahigashi-cho, Kodaira, Tokyo 187-8553, Japan

Tel +8 I 4234 I 27I I

Fax +8I 423446745

Email hkashiwagi@ncnp.go.jp

\section{Case report}

The nature of this publication was explained to the patient, and written consent was obtained. The present case involved a 24-year-old man (birthweight 1,400 g) who was 
diagnosed with tetralogy of Fallot. He did not have a history of seizures before hospitalization. His father, but not mother, also had schizophrenia (the patient has no siblings). A history of mental illness or other malformations, including heart diseases, was not evident in other members of his family. The patient underwent surgical intracardiac repair for tetralogy of Fallot at age 3, and has been receiving regular follow-up evaluations since then. The patient is a nonsmoker.

At age 19, the patient began experiencing command auditory hallucinations and thought broadcasting, and was diagnosed with schizophrenia. He was not responsive to treatment with antipsychotic drugs, including risperidone (3-6 mg/day) and paliperidone (dose unknown). He was treated with risperidone between age 19 and 20, but did not see a psychiatrist between age 20 and 21 . Then, treatment with paliperidone was started when he was 21 , which was continued for 1 year. He sometimes held a part-time job until age 21, when he was fired. He became withdrawn thereafter. The patient developed communication deficits and his hallucinatory and delusory behaviors became prominent. In addition, delusions of grandeur became systematic, and he repeatedly exhibited sudden violent behaviors. When the patient was 22 years old, he injured another person seriously while in a hallucinatory-paranoid state, and was hospitalized in the forensic ward.

While hospitalized, the patient was unresponsive to haloperidol (up to $12 \mathrm{mg} /$ day), risperidone (12 mg/day), and olanzapine (20 mg/day). He exhibited pathological polydipsia and water intoxication, resulting in a blood sodium level of $120 \mathrm{mEq} / \mathrm{L}$ and tonic-clonic seizures. These observations indicated that the patient had treatmentresistant schizophrenia.

Twelve months after the initial hospitalization, he was transferred to our section to start clozapine therapy. The patient was $154 \mathrm{~cm}$ tall and weighed $47 \mathrm{~kg}$. His intelligence quotient was 79, as measured by the Wechsler Adult Intelligence Scale-III. The patient's face had characteristics of velo-cardio-facial syndrome, as he had a prominent nose with a bulbous tip, malar flatness, and a small mouth. ${ }^{5} \mathrm{He}$ also exhibited hypernasal speech, short stature, and slender hands, but did not have a cleft palate or hypocalcemia. ${ }^{5}$ An echocardiogram indicated a left ventricular ejection fraction of $36 \%$, mild mitral regurgitation, moderate tricuspid regurgitation, and abnormal interventricular septal motion. Holter monitoring revealed a tendency to exhibit sinus tachycardia. Blood biochemistry analyses revealed that the brain natriuretic polypeptide level was slightly elevated at $20.6 \mathrm{pg} / \mathrm{mL}$. Chromosomal analysis by fluorescence in situ hybridization (FISH) revealed neither deletion nor duplication of 22q.11.2.

Clozapine treatment was started 13 months after the initial hospitalization. Its administration began at $12.5 \mathrm{mg}$, and the amount was subsequently increased by $25 \mathrm{mg}$ every 2-3 days over the initial 3 weeks until it reached $200 \mathrm{mg}$. Thereafter, the dosage was increased by 25-50 mg each week, bringing the amount up to $400 \mathrm{mg}$ over the first 2 months from the beginning of administration. We did not measure blood levels of clozapine. No co-administration of other antipsychotic drugs were prescribed. Then, the communicability of the patient improved drastically and auditory hallucinations and delusions stopped affecting his activities of daily living. As his violent behaviors and pathological polydipsia were alleviated, the patient was able to participate in a group therapy program consistently.

Tonic-clonic seizures were observed 2 weeks after titrating clozapine to $400 \mathrm{mg} /$ day. In addition, electroencephalography showed frequent high-amplitude spike waves, mainly in the left temporo-occipital region in the basic rhythm of high-amplitude slow waves. In contrast, magnetic resonance imaging of the brain did not show abnormalities other than mild cerebellar atrophy. Therefore, the clozapine dose was reduced to $300 \mathrm{mg} /$ day, and $600 \mathrm{mg} /$ day of valproic acid was added.

Echocardiography 6 months after the start of clozapine revealed no significant changes in cardiac functions. In addition, the brain natriuretic polypeptide level was decreased to $10.5 \mathrm{pg} / \mathrm{mL}$. Seven months after commencing clozapine treatment, convulsive seizures recurred. At that time, the blood concentration of valproic acid was $70.3 \mu \mathrm{g} / \mathrm{mL}$, which was within the therapeutic range. Therefore, topiramate was added, and the dose was gradually increased to $200 \mathrm{mg} /$ day. The convulsive seizures ceased and spike waves disappeared. The dose of clozapine was increased to $450 \mathrm{mg} /$ day. Seventeen months after the start of clozapine treatment, psychiatric symptoms was stabilized, and seizure episodes were no more present. Currently, the patient is engaged in leisure activities, work, and group therapy programs.

\section{Discussion}

To our knowledge, we report here the first case of schizophrenia comorbid for tetralogy of Fallot without the 22q.11.2 deletion, in a patient who responded well to clozapine.

Patients with schizophrenia with the 22q.11.2 deletion have been shown to respond well to a relatively low-dose clozapine, with a greater likelihood of developing convulsive seizures induced by the drug. ${ }^{3,5}$ Gothelf et $\mathrm{al}^{5}$ reported a case of 
schizophrenia with tetralogy of Fallot with 22q.11.2 deletion, whose psychotic symptoms and violent behavior were improved by clozapine $200 \mathrm{mg} /$ day. Occurrence of clozapineinduced seizures was prevented by adding valproic acid, at $600 \mathrm{mg} /$ day, which induced myotonic jerks. ${ }^{5}$ Mild diffuse atrophy of the cortex and cerebellar vermis was also identified in that case. ${ }^{5}$ These observations may be contrasted with those of the patient (without 22q.11.2 deletion) in our report, who responded well to clozapine, but co-administration of the same dose of valproic acid (600 $\mathrm{mg}$ /day) by itself did not prevent seizure recurrence. Whether the mild cerebellar atrophy, observed in both cases, is associated with vulnerability to developing clozapine-induced seizures deserves further investigations.

Kushima et al identified CNVs, including 22q.11.2 or Xp.22.31 deletion, in $~ 9 \%$ of Japanese or Taiwanese patients with schizophrenia. ${ }^{6}$ In their study, $\sim 40 \%$ of patients with CNVs had a history of congenital or developmental phenotypes, and the incidence of treatment resistance was significantly higher. ${ }^{6}$ While FISH did not reveal 22q.11.2 deletion or duplication in our patient, no other chromosomal tests were conducted. Therefore, it is unclear whether he has other types of CNVs. Convulsive seizures triggered by clozapine are reported to occur more frequently in patients with the 22q.11.2 deletion. ${ }^{3}$ Future surveys should be conducted to investigate the relationships between clozapine-induced convulsive seizures and CNVs other than 22q.11.2.

Limited data exist with regard to the selection of antiepileptic drugs for clozapine-induced epilepsy. ${ }^{3,4}$ A previous report suggests the effectiveness of valproic acid for clozapineinduced epilepsy. ${ }^{4}$ Gabapentin, lamotrigine, and topiramate have also been used to manage seizures in clozapine users. ${ }^{4}$
Specifically, there has been little information on the type of antiepileptic drugs effective for treating or preventing clozapine-induced seizures in schizophrenia patients with 22q.11.2 deletion and tetralogy of Fallot. On the other hand, the present case, comorbid with the cardiac anomaly but without 22q.11.2 deletion, was successfully treated with clozapine at doses that triggered seizures by co-administration with valproic acid and topiramate. Clearly, additional studies are warranted to determine which antiepileptic drugs should be recommended as an adjunctive therapy for clozapine treatment, in association with information on CNVs.

\section{Acknowledgments}

The authors thank the patient, who kindly gave us permission to publish his treatment experience. This study was not supported by any pharmaceutical companies or agencies.

\section{Disclosure}

The authors report no conflicts of interest in this work.

\section{References}

1. Apitz C, Webb GD, Redington AN. Tetralogy of Fallot. Lancet. 2009; 374(9699):1462-1471.

2. Bassett AS, Chow EW, Husted J, et al. Clinical features of 78 adults with 22q11 Deletion Syndrome. Am J Med Genet A. 2005;138(4):307-313.

3. Butcher NJ, Fung WL, Fitzpatrick L, et al. Response to clozapine in a clinically identifiable subtype of schizophrenia. Br J Psychiatry. 2015; 206(6):484-491.

4. Williams AM, Park SH. Seizure associated with clozapine: incidence, etiology, and management. CNS Drugs. 2015;29(2):101-111.

5. Gothelf D, Frisch A, Munitz H, et al. Clinical characteristics of schizophrenia associated with velo-cardio-facial syndrome. Schizophr Res. 1999;35(2):105-112.

6. Kushima I, Aleksic B, Nakatochi M, et al. High-resolution copy number variation analysis of schizophrenia in Japan. Mol Psychiatry. 2017; 22(3):430-440.

\section{Publish your work in this journal}

Neuropsychiatric Disease and Treatment is an international, peerreviewed journal of clinical therapeutics and pharmacology focusing on concise rapid reporting of clinical or pre-clinical studies on a range of neuropsychiatric and neurological disorders. This journal is indexed on PubMed Central, the 'PsycINFO' database and CAS, and is the official journal of The International Neuropsychiatric Association (INA). The manuscript management system is completely online and includes a very quick and fair peer-review system, which is all easy to use. Visit http://www.dovepress.com/testimonials.php to read real quotes from published authors. 